\title{
Correction to: Pretreated Indian Gooseberry (Emblica officinalis) Segments: Kinetic, Quality and Microstructural Parameters
}

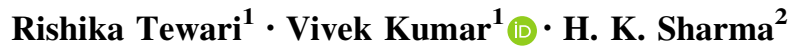

Accepted: 14 June 2021 / Published online: 23 June 2021

(C) The Institution of Engineers (India) 2021

Correction to: J. Inst. Eng. India Ser. A (June 2021) 102(2):523-534
https://doi.org/10.1007/s40030-021-00538-9

The original version of the article, published on 17 May, 2021 in volume 102, issue 2, page 523-534 contained a mistake. The citation references in Table 1 were incorrect. The corrected version is given below.
Publisher's Note Springer Nature remains neutral with regard to jurisdictional claims in published maps and institutional affiliations.

The original article can be found online at https://doi.org/10.1007/s40030-021-00538-9.

Vivek Kumar

viveksachan99@rediffmail.com

1 Department of Food Technology, Harcourt Butler Technical University, Kanpur, Uttar Pradesh 208002, India

2 Department of Food Engineering and Technology, Sant Longowal Institute of Engineering and Technology, Longowal, Punjab 148106, India 


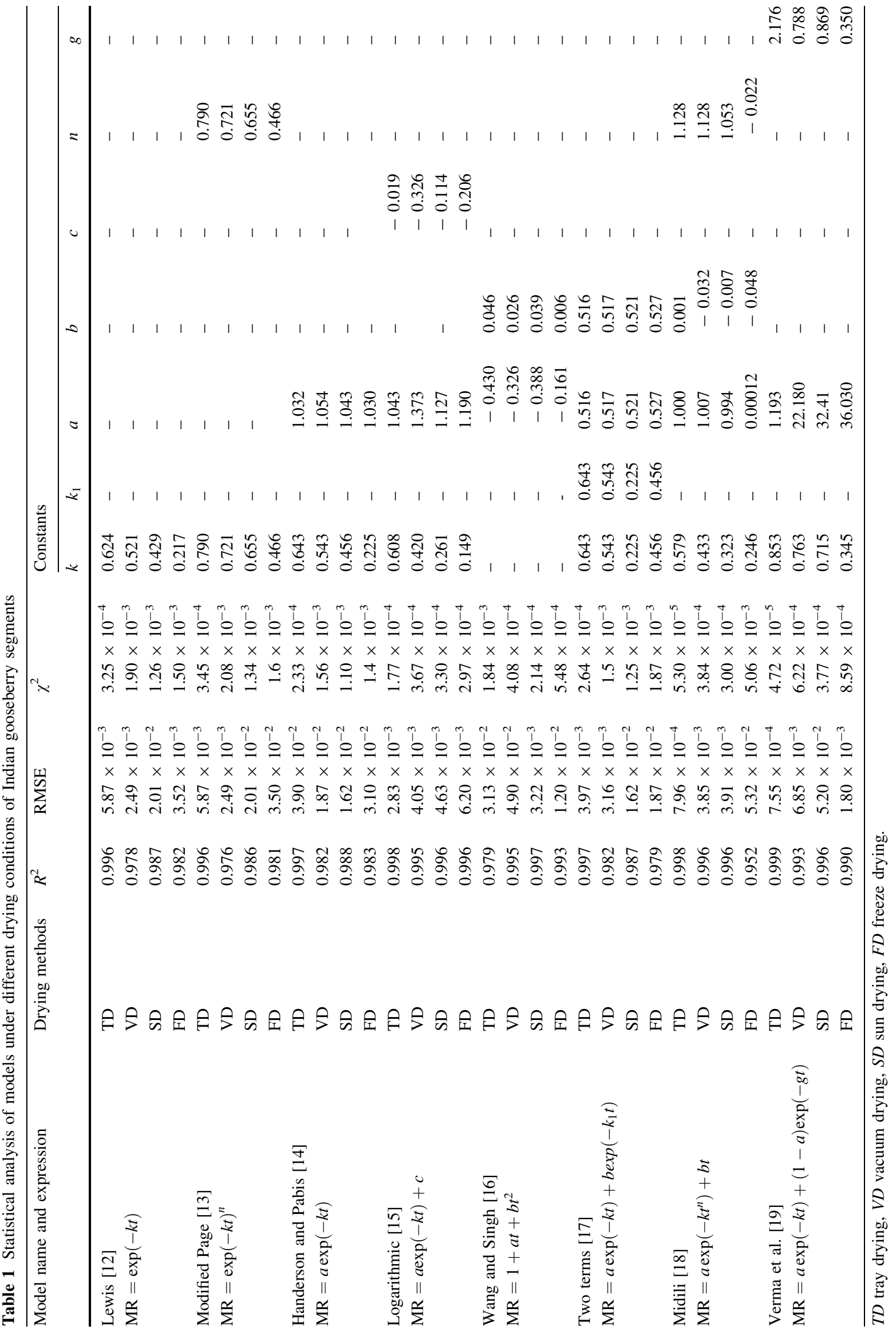

